\title{
Correction to: Concomitant onset of systemic lupus erythematosus and disseminated histoplasmosis: a case-based review
}

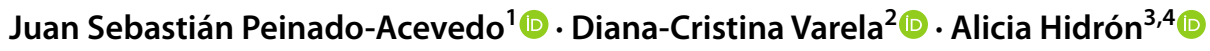

Published online: 21 December 2020

c) Springer-Verlag GmbH Germany, part of Springer Nature 2020

\section{Correction to: Rheumatology International https://doi.org/10.1007/s00296-020-04739-6}

In the original article published, the given name and the family name of all the authors are interchanged as given in the original manuscript. The correct names are: Juan Sebastián Peinado-Acevedo, Diana-Cristina Varela, Alicia Hidrón.
The original article has been corrected.

Publisher's Note Springer Nature remains neutral with regard to jurisdictional claims in published maps and institutional affiliations.

The original article can be found online at https://doi.org/10.1007/ s00296-020-04739-6.

Diana-Cristina Varela

dianacristinavarela@gmail.com

1 Departament of Internal Medicine, Universidad de Antioquia, Hospital Universitario San Vicente Fundación, Medellín, Colombia

2 Departament of Rheumatology, Universidad Pontificia Bolivariana, Medellín, Colombia

3 Department of Infectious Diseases, Hospital Pablo Tobón Uribe, Medellín, Colombia

4 Department of Medicine, Universidad Pontificia Bolivariana, Medellin, Colombia 